\title{
UM ESTUDO SOBRE A PARTICIPAÇÃO DOS CORONÉIS BORGISTAS NOS CONFLITOS ARMADOS DA REPÚBLICA VELHA RIO-GRANDENSE
}

Maristela Silva Pereira*

Este artigo faz parte de um trabalho mais amplo, a Dissertação de Mestrado, por mim apresentada e aprovada na PUCRS em setembro de 1993, sob o título: "Os Corpos Provisórios da Brigada Militar. Seus Aspectos Sociais e Utilitários (1923-1927)".

Uma das premissas da Dissertação era investigar os fatores que concorreram para o surgimento dos Corpos Provisorios ${ }^{1}$ a partir da Revolução de 1923 no Rio Grande do Sul. Considerando-se que não foi somente o aspecto bélico que impulsionou o governo estadual na organização dos referidos Corpos, foi possível entender que não havia apenas um agente determinante naquele contexto.

Sendo assim, a existência de Corpos Provisórios concebida dentro de uma conjuntura política, econômica e social específica onde está inserida a

* Mestre em História do Brasil pela PUCRS.

1 Grupos de voluntários arregimentados pelo governo estadual para lutar nos conflitos armados regionais.

Estudos Ibero-Americanos. PUCRS, v.XX, n.2, p. 27-43, dezembro, 1994 
própria ação dos coronéis borgistas para a formação e comando das forças auxiliares da Brigada Militar.

A partir de cartas, telegramas, relatórios, ofícios e uma bibliografia pertinente ao tema, foi possível enfocar a participação dos coronéis borgistas através da caracterização dos seus interesses específicos nos conflitos armados do período citado.

\section{A CRISE DA REPÚBLICA VELHA}

No início dos anos vinte, o Rio Grande do Sul passava por uma crise política e econômica que acabou por se transformar em um conflito armado. Foi a chamada Revolução de 1923.

A análise do período final da Primeira República no Rio Grande do Sul demonstra que, desde o início do século, o Estado movimentou bastante sua economia com a expansão da lavoura de arroz, ampliação das vias de transporte e melhoria do sistema bancário, com o surgimento do Banco Pelotense em 1906.

Deve-se à política de Júlio de Castilhos esta modernização dos múltiplos setores econômicos, com o objetivo de um desenvolvimento global, não mais privilegiando apenas o setor pecuário.

Conjugando vários fatores, o conflito armado de 1923, se caracterizou pela luta no interior da classe dominante gaúcha; onde uma facção de elite pecuarista não mais conseguia apoio e privilégios do governo estadual, começando assim uma forte oposição a Borges de Medeiros.

Foi após a I Guerra Mundial que se estabeleceu uma crise econômica sem precedentes para os pecuaristas, pois, durante a guerra, abriram-se novas possibilidades de mercado para as regiôes produtoras de gêneros alimentícios. Assim sendo, os pecuaristas rio-grandenses tiveram mercados garantidos, nesta época em que se iniciava um período de euforia.

Entretanto, ao término da guerra, os países beligerantes passaram a conter as despesas e, conseqüentemente, decaiu a demanda dos produtos agropecuários. Com a queda dos preços, o mercado da carne do Rio Grande do Sul passou a enfrentar uma situação crítica. Segue-se a isso a diminuição do abate, a falta de créditos e a concorrência no mercado interno. Conforme Pesavento:

"O Rio Grande do Sul, em especial, era responsável por uma grande quota das exportaçōes dos produtos frigoríficos que o 
Brasil envia às nações combatentes. Com a retenção do mercado internacional (...), à volta da economia de guerra, a economia de paz motivou a volta dos preços (...). Ante a crise de mercado, os frigoríficos restringiram a matança, que, conjugada com a restrição do abate nas charqueadas, criou para a pecuária gaúcha, uma crise sem precedentes." ${ }^{2}$

A situação se agravava, pois as casas bancárias que haviam feito empréstimos aos criadores, na época da euforia, agora determinavam a devolução do capital concedido.

Os criadores, sem terem para quem vender seu gado, e não tendo como pagar as dívidas contraídas, foram à falência. Muitos pecuaristas "em desespero por não poderem saldar seus empréstimos suicidaram-se". ${ }^{3}$ Os estanceiros não conseguiam atingir a lucratividade necessária para cobrir os investimentos feitos. A crise da pecuária gerou uma crise financeira da qual os pecuaristas não tinham condições de saírem sozinhos.

Diante desta situação, a classe pecuarista passa a invocar o "amparo e proteção ao Estado, a fim de que este assegurasse a lucratividade dos investimentos e mantivesse as condições de reprodução das relações sociais dominantes". ${ }^{4}$ Os pecuaristas reivindicavam ao governo estadual auxílio para superar a crise, com a redução do preço dos fretes ferroviários, a concessão de empréstimos e juros mais baixos, com longos prazos; também solicitavam medidas que defendessem o mercado interno da concorrência das charqueadas platinas. Todavia, as medidas de defesa solicitadas não foram atendidas.

O Presidente Borges de Medeiros segue a linha castilhista e, em nome de uma política econômica de desenvolvimento global, vê-se na impossibilidade de atender exclusivamente ao setor pecuário. ${ }^{5}$

2 PESAVENTO, Sandra. República Velha Gaúcha: charqueadas - frigoríficos criadores. Porto Alegre: Movimento, 1980, p. 178.

3 SANTOS, Mariza Elaine S. Honório Lemos, um líder carismático. Porto Alegre: PUCRS, Dissertação de Mestrado. História do Brasil, 1988, p. 64.

4 ANTONACCI, Maria A. RS as oposições \& a revolução de 1923. Porto Alegre: Mercado Aberto, 1981, p. 39.

5 Júlio de Castilhos ao consolidar a República no RS, adotou os pressupostos filosóficos de Augusto Conte (positivismo) como doutrina ideológica. A morte de Castilhos em 1903, da início a uma "nova etapa que se prolonga até 1915, corresponde a efetiva difusão do positivismo, na versāo castilhista". BOEIRA, Nelson. RS Cultura e Ideologia. Porto Alegre: Mercado Aberto, 1990, p. 40. Porto Alegre, 1980, p. 40. Borges de Medeiros sucedeu-o na presidência do Estado e nas tradições positivistas 
Em virtude das sucessivas negativas do governo estadual perante as suas solicitações, a parcela afastada do poder passa a considerar insuportável a dominação do PRR (Partido Republicano Rio-grandense). Forma-se, então, um bloco oposicionista sob a liderança de Assis Brasil para disputar as eleições presidenciais de $1922{ }^{6}$

Com a vitória de Borges, em 1922, a oposição não aceitou os resultados eleitorais, alegando fraude, em decorrência deste fato, e sem haver nenhuma possibilidade de entendimento entre as partes, o grupo assisista vai às armas, na luta pelo poder no Rio Grande do Sul.

A partir de janeiro de 1923, o governo do Estado passa a organizar as forças auxiliares da BM para combaterem os revolucionários. Quanto a formação desses CPs, assim explica Hélio Moro Mariante:

"(...) sua instituição e criação era uma necessidade. Desde a velha Roma com suas milícias e em grande evidência na Revolução Francesa... a história vem registrando a atuação desses Corpos de patriotas, em quase todos os países... era uma necessidade na época, pois que não podiam os governos manter, permanentemente um Exército numeroso, capaz de fazer face às constantes agitações do tempo."

É certo que em época de conflito se faz necessário o aumento dos contingentes militares. Todavia, em 1923 se tem uma conjuntura onde a organização desses Corpos não correspondeu apenas às necessidades bélicas do momento. Importa buscar a existência dos provisórios relacionando-a com a problemática sócio-política e econômica daquele contexto.

de "promover no RS um desenvolvimento econômico multilateral (...) pelo progresso de todos os ramos setoriais da economia e não por um em especial". PESAVENTO, Sandra J. República Velha Gaúcha: charquadas - frigoríficos - criadores, p. 197.

6 Sobre a unificação das oposiçōes em torno da candidatura de Assis Brasil, importante observar as considerações de Paulo Vizentini: "A reunificação das oposiçōes riograndenses em torno da candidatura Assis Brasil não pode, ser explicada apenas pela conjuntura de crise econômica no pós-primeira Guerra. Ela resulta, historicamente, de uma tendência ao nível político, de reestruturação das oligarquias conservadoras liberais. O segundo fator de natureza política prende-se ao crescimento significativo da fraude e violência políticas, devido ao desgaste do borgismo enquanto sistema político estadual". VIZENTINI, Paulo F. A crise dos anos 20. Porto Alegre, Editora da Universidade Federal do RS, 1992, p. 24-5.

7 MARIANTE. Hélio Moro. Crônica da Brigada Militar Gaúcha. Porto Alegre: Imprensa Oficial, 1972, p. 169-70. 
O autor Hélio Moro Mariante parte do pressuposto de que era inevitável a organização dos CPs devido às necessidades militares do momento, concebendo este fato como historicamente determinado, sem relacionar sua existência com o momento e a problemática econômica, política e social daquele contexto. A observância destes itens demonstra que os CPs tiveram um caráter utilitário amplo, pois sua existência beneficiou a três esferas de interesses distintos: governo, coronéis e população, que, estando em constante relação de forças, tornaram-se agentes naquele processo social.

O ressurgimento dos CPs em 1923 não foi somente uma atitude do governo estadual que através de suas legislaçōes procurou aumentar os contingentes militares da BM para atender às necessidades do momento conflituoso.

Trata-se de entender que na sociedade o poder não se encontra em só lugar, não exercido por um indivíduo apenas, tampouco é o Estado o detentor do poder em si. $^{8}$

Sendo assim, é possível entender que foi a ação conjunta, embora distinta, entre Estado, coronéis e população, que viabilizou a existência dos CPs, por ocasiāo dos conflitos armados na década de vinte no Rio Grande do Sul. Não houve, portanto, um único agente determinante neste contexto, pois os CPs surgiram como alternativa momentânea e eficiente para solucionar questôes específicas dos seus Agentes.

Tendo presente estas colocações, torna-se importante um estudo particularizado dos setores envolvidos para que se possa delimitar interesses, formas de ação e amplitudes de atuações.

\section{UM CORPO PROVISÓRIO. UM BOM NEGÓCIO}

Em relação aos coronéis borgistas, ligados ao ramo da pecuária, nota-se um interesse em comandar e organizar CPs. Este fato, de uma forma geral, concorreu para o surgimento de vários grupamentos "avulsos" pelo interior do Estado e também para o elevado contingente bélico que formouse a partir de 1923.

8 FOUCAULT, Michel. Microfísica do Poder. 9. ed. Rio de Janeiro: Graal 1990, p. 183. "O poder deve ser analisado como algo que circula, ou melhor, como algo que só funciona em cadeia. Nunca está localizado aqui ou ali, nunca está nas mãos de alguns". 
Com a crise econômica no Estado, também os coronéis borgistas, ligados ao ramo da pecuária, passavam por um momento difícil, pois a política econômica do governo estadual prejudicava seus interesses. Porém, as vantagens decorrentes de um relacionamento feito na base da troca de favores, explica a permanência dos coronéis leais a Borges de Medeiros.

Referindo-se aos representantes pecuaristas que continuavam fiéis ao borgismo, observa Loiva de O. Felix:

"Todos estavam ressentidos por verem seus interesses econômicos prejudicados pela política oficial do Estado. Ocorre, porém, que as vantagens políticas advindas do relacionamento dos coronéis leais, ponta de lança do borgismo do interior do Estado, sobepunham-se às possíveis perdas econômicas individuais". 9

O governo atendia os interesses individuais e políticos dos correligionários, que podiam ser tanto a concessāo de cargos públicos como a construção de uma estrada, ou até mesmo o comando de um Corpo Provisório, por ocasião do conflito armado em 1923.

Embora Loiva O. Felix relacione o comando dos CPs à articulação do poder do aparelho estadual com as bases locais, tanto para os momentos de conflito armado quanto para o momento das eleiçōes, não está explicado que esse mecanismo tenha exercido apenas estas funçōes. ${ }^{10}$ Tampouco, a "satisfação pessoal" ou a "vaidade do mando" podem explicar o interesse dos coronéis em comandar um Corpo Provisório.

A mesma autora, analisando o "coronelismo" na região serrana e sua relação com o poder estadual, destaca que a participação dos coronéis no "jogo político não era totalmente desprovido de sentido", ${ }^{11}$ pois seus interesses pessoais específicos os levavam à opção partidária.

A vantagem advinda do comando de um $\mathrm{CP}$, para os coronéis ligados ao ramo da pecuária, seria a de poder organizar os peōes e agregados em

9 FELIX, Loiva O. Coronelismo-borgismo e cooptação política. Porto Alegre: Mercado Aberto, 1987, p. 142.

10 FELIX, Loiva O. Op. cit., p. 118. A autora Loiva O. Felix relaciona a chefia dos CPs apenas à questão política e questões pessoais dos coronéis e nāo às possíveis vantagens financeiras, porque seu trabalho examina o coronelismo na regiāo serrana, onde havia uma cultura diversificada e os donos de terra não se dedicavam especificamente à pecuária. Portanto, não enfrentavam crise econômica que se compare a dos pecuaristas da região do planalto e fronteira.

11 FELIX. Op. cit., p. 117. 
volta do seu comando, pelo tempo que durassem os conflitos, sendo que o governo estadual subsidiaria a alimentação da tropa, a vestimenta e os ordenados. $^{12}$

Sendo assim, os coronéis borgistas, além de poderem aglutinar uma mão-de-obra que possivelmente seria liberada devido a crise do setor de pecuária, também conseguiram o respaldo financeiro do governo estadual para mantê-la.

Todavia, não existiam apenas estes interesses de ordem geral. Havia também interesses específicos e particulares, que manifestavam os poderes que esta classe social detinha. ${ }^{13}$

Neste sentido, se pode observar que, por oportunidade do conflito armado de 1923, os interesses dos coronéis, inclusive motivados pela crise econômica da pecuária, se fizeram notar com maior nitidez. Nesta ocasiāo o comando e/ou organização de um $\mathrm{CP}$ comportava também algumas vantagens materiais. Não se tratava apenas de vaidade pessoal - embora este aspecto possa estar presente - mas de uma questão financeira inclusive.

Já no início dos conflitos em 1923, era notório o interesse dos coronéis borgistas em comandarem CPs. Neste período, o então comandante geral da BM, Cel. Emílio Massot, recebia correspondências de coronéis que solicitavam a organização ou comando de CPs.

As correspondências do Comando Geral da BM trazem informaçōes a esse respeito. Como esta carta, expedida pelo Cel. Massot ao amigo Cel. Claudino, informando-lhe sobre as pretensões de um já conhecido Cel. João Francisco.

"O coronel João Francisco seguidamente me escrevia cartas manifestando seu desejo de vir prestar serviços no sul na actual emergência.

12 Conforme FERREIRA Filho, Arthur. Revoluçāo de 1923. Porto Alegre: Imprensa Oficial, 1973, p. 30. "O governo oferecia a seus defensores vantagens que os revolucionários nāo podiam oferecer, como fardamentos, melhores armas, um pequeno soldo e garantia de reforma remunerada aos mutilados e de uma pensão às viúvas ou filhos dos mortos em combate."

13 MACHADO, Roberto. "Por uma geneaologia do poder". In: FOUCAULT, Michel. Microfísica do poder. p. 12. Michel Foucault, na sua análise do poder, indica a existência de poderes periféricos e moleculares que não são necessariamente criados pelo Estado; e mesmo que nasçam fora dele não são inevitavelmente reduzidos a uma forma ou manifestação do aparelho central. "Os poderes se exercem em níveis variados e em pontos diferentes da rede social, e neste complexo, os micropoderes existem integrados ou não ao Estado". 
Até numa de suas últimas cartas se propunha a ficar addido em quaisquer serviços.

Diante dessas suas manifestações, passei-lhe telegrama, de que lhe envio cópia, offerecendo-lhe, até nova solução, o comando de Corpo e perguntando ainda a importância que precisava para seu transporte, isto porque elle sempre me dizia, nas suas referidas cartas, estar pobre e em precárias condições de recursos. (Grifo nosso)

A este meu telegrama respondeu elle com o que lhe envio e no qual declara não aceitar o commando de um Corpo, demonstrando desejar cargo mais elevado.

Nessas condições parece que devemos deixar de parte esse homem e mesmo, em reserva, the declaro que assim pensa o Presidente". ${ }^{14}$

Na situação apresentada, pode-se notar a existência de uma íntima relação entre o comando de $\mathrm{CP}$ e as dificuldades financeiras por que passavam os coronéis. Por este motivo, é possível entender que a oportunidade de organizar um $\mathrm{CP}$ representava também a possibilidade de obter alguns benefícios. Portanto, as solicitações tinham motivos plausíveis.

Segundo Alfredo Jacques:

"As folhas de vencimentos acusavam o efetivo de quatrocentos homens, quando, na realidade, existiam duzentos. O comandante embolsava o resto... Negócio lucrativo o tal de "provisórios". Inúmeras hipotecas foram levantadas. Muita gente se aprumou, do lindo". ${ }^{15}$

Não se pode, evidentemente, generalizar tais consideraçōes, pois havia uma estreita relação de tais atitudes com a região a que pertencia o Corpo. Sendo assim, eram os Corpos organizados em regiões onde predominava a pecuária e a crise econômica, que serviam de fonte de lucro. (Ver Mapa na página seguinte).

"Num Corpo, na fronteira, em 1924, jamais tinha visto tamanha roubalheira. Roubava o comandante, o fiscal, o quartel-mestre. Um avanço geral, todo mundo roubava". ${ }^{16}$

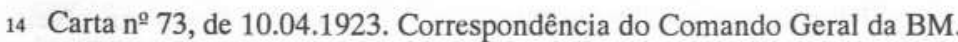

15 JACQUES, Alfredo. Os Provisórios. Porto Alegre: Globo, 1938, p. 40.

16 JACQUES, Alfredo. Os Provisórios. Op. cit., p. 39. 
Em decorrência dos seus interesses financeiros, os coronéis também procuravam aumentar o efetivo dos CPs, que o Cel. Massot respondia: "não havia necessidade de criar novos esquadrões", ${ }^{17}$ ou que "o número de pessoal do Corpo deve, por enquanto, ficar limitado ao efetivo estabelecido". ${ }^{18}$

Por vezes as tentativas de lucro eram infrutíferas, como demonstra a seguinte correspondência:

\section{"Saudações,}

Restituo-vos as folhas de vencimento do esquadrão sob vosso commando, não só por estarem mal organizadas como também porque de accordo com o que está combinado, o thesouro do Estado pagará a metade da despesa e a outra metade correrá por conta desse município. Assim as folhas de vencimentos só poderão ser enviadas depois da creação do $1^{\circ}$ Corpo Provisório por Decreto $\mathrm{n}^{0} 3.151$ de 12 do corrente, e do qual fará parte o esquadrão dessa localidade". ${ }^{19}$

A intenção do capitão João Maciel da Rosa, seria a de tentar receber antecipadamente os valores correspondentes à folha de pagamento do esquadrāo que havia organizado.

Assim como este, também outros contingentes provisórios iam sendo formados, até mesmo sem o conhecimento do Cel. Massot, que só ficava sabendo de sua existência quando lhes eram enviadas as folhas de pagamento. $^{20}$

Um outro instrumento que oportunizava aos coronéis a obtenção de vantagens eram as requisições. Quando um Corpo necessitava de alimentos, cavalos ou qualquer artigo para sua utilização, o comandante do Corpo adquiria tais utensílios mediante requisição. Posteriormente, a pessoa inte-

17 Telegrama $\mathrm{n}^{\mathrm{O}} 1525$, de 01.12.1924. Correspondência do Comando Geral. MBM.

18 Telegrama $\mathrm{n}^{2} 1468$, de 27.11.1924. Correspondência do Comando Geral. MBM.

19 Cartâo n ${ }^{2} 101$ do Cel. Massot ao Com. do esquadrão Santo Antônio da Patrulha, 14.05.1923. Correspondência do Comando Geral. MBM. Embora, o Com. João Maciel da Rosa seja capitão, isto não comprova que o mesmo seja militar, pois o comando dos esquadrōes também era dados aos coronéis borgistas e seus familiares.

20 Assim demonstra o ofício n⿳0 386 de 16.05.1923, o Cel. Massot envia ao Presidente Borges de Medeiros as folhas de vencimento de um Contingente desconhecido. "Com este vos envio as folhas de vencimentos relativas aos meses de fevereiro, março e abril de um destacamento policial do município de Cangussu, sobre as quais este commando nada pode informar". 
MAPA 1 - Representação da densidade da população bovina $/ \mathrm{km}^{2}$

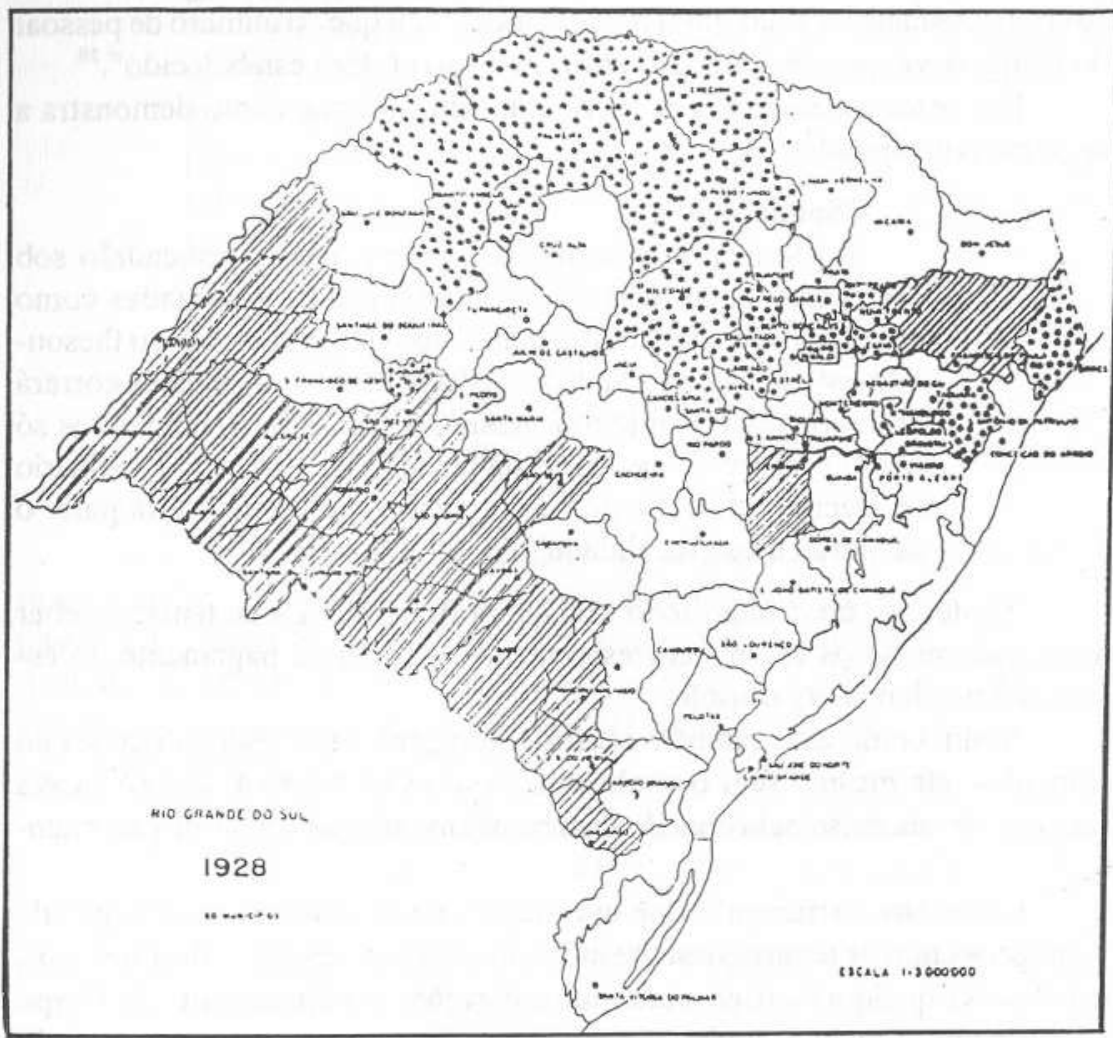

MAPA: Evolução Administrativa do Rio Grande do Sul (Criação dos municípios). IGRA (Instituto Gaúcho de Reforma Agrária). Divisão de Geografia e Estatística, p. 51. CONVENÇÃO: Menos de 20 cabeças $/ \mathrm{km}^{2}$

Entre 20 e 50 cabeças $/ \mathrm{km}^{2}$

Mais de 50 cabeças $/ \mathrm{km}^{2}$

ressada enviava a documentação comprobatória para o Comando Geral, solicitando ressarcimento.

O Cel. Massot apreciava a documentação e, no caso de tudo estar em ordem, destinava o pedido ao Tesouro do Estado para ser efetivado o pagamento. 
Já em março de 1923, através do Decreto n²3.114, o governo do Estado estabelecia as formas de aquisição das subsistências que deviam ser por compra direta ou requisição. Somente era permitida a aplicação deste decreto para:

(...) a obtenção de víveres, forragens, animais, combustíveis e meios de transporte... além do que estava previsto no decreto, requisitou-se também, muitas vezes, medicamentos, capas e roupas de inverno". ${ }^{21}$

Entretanto, alguns outros utensílios e objetos, não relacionados acima, também eram requisitados pelas forças provisórias. Por vezes, tais artigos não destinavam-se à utilidade militar como ilustra o exemplo a seguir, no qual o Cel. Massot consulta o Presidente Borges de Medeiros a respeito de uma requisição duvidosa.

"Os documentos que acompanham a conta a que se refere este requerimento estão assignados pelo Dr. Oswaldo Aranha, commandante do $5^{\mathrm{Q}}$ Corpo da $2^{\mathrm{a}}$ Brigada Provisória do Oeste; devo, porém chamar a attenção para os artigos adquiridos os quais não parecem destinados ao uso dos soldados, tais são camisas e ceroulas de Zaphir de elevados preços, meias, lenços de seda, abotoaduras e outros, etc. ...". ${ }^{22}$

Embora não seja possível fazer atribuiçōes a respeito de quem teria feito as requisições citadas no documento, é importante observar-se que a mesma fora assinada pelo comandante do Corpo. Razão pela qual, o Dr. Oswaldo Aranha era conivente com a compra de tais artigos que, serviriam para o uso pessoal de alguém que já estivesse familiarizado com artigos finos. Neste caso, não seriam os soldados os interessados e sim a oficialidade e o próprio comandante, Dr. Oswaldo Aranha.

Neste sentido, nāo se pode considerar que mesmo aqueles coronéis abastados da região serrana, por exemplo, onde a crise econômica se fazia em menores proporções, ${ }^{23}$ não tivessem subtraído alguma vantagem.

21 RIBEIRO, Aldo Ladeira. Esboço Histórico da Brigada Militar. Porto Alegre: Oficinas Gráficas da Brigada Militar, 1953, v. 2, p. 56.

22

Informação $\mathrm{n}^{\circ} 60$, de 04.6.1923. Lançada no requerimento em que a firma de Pedro Surreaux \& Cia. pede pagamento da quantia de 12:076\$830. Correspondência do Comando Geral, MBM. 
A imagem de um coronel que dispunha de seus próprios recursos financeiros em favor do Corpo que chefiava é viável. Porém, é importante se observar que tais gastos tinham um ressarcimento posterior. Isto é demonstrado através de uma carta do comandante do destacamento de Santa Catarina que intercede em favor do Cel. Vazulmiro Dutra, ${ }^{24}$ junto ao Cel. Massot, para que este mandasse indenizar uma quantia gasta pelo referido coronel.

"QG de Palmas, Santa Catarina, 03.11.1924. Peço as vossas providências para que o tenente-coronel Vazulmiro Dutra $\mathrm{Cmt}$. do $3^{2} \mathrm{Btl}$. Militar do Rio Grande seja indenizado da quantia de 2:050\$000, que do seu bolso gastou com o transporte de vários destacamentos para Palmeira, e do seu Btl. para Santa Bárbara, conforme recibo que me apresentou.

A falta de recursos e mesmo de competência para resolver tal assunto, pois as referidas despesas foram feitas antes do Btl. ser incorporado ao meu dest., levou-me a recorrer aos vossos officios junto a quem de direito.

Vasco da Silva Varella". ${ }^{25}$

Portanto, as despesas feitas pelos Corpos eram restituídas posteriormente, mediante documentação comprobatória a quem tinha direito. Nesta situação se encontravam muitos comerciantes e estanceiros que por vezes eram os próprios comandantes dos Corpos.

Um relatório do Cel. Claudino Nunes Pereira, comandante da $5^{\text {a }}$ Brigada Provisória do Centro, discorre sobre o gado abatido entre 18 de agosto a 20 de dezembro de 1923 pela sua Brigada. O referido relatório apresenta mais alguns aspectos da realidade sobre as requisições. No período citado, a $5^{\text {a }}$. Brigada abateu cerca de 1.052 reses que foram assim distribuidas pelas Unidades que a compunham.

23 Segundo PESAVENTO, Sandra. República Velha Gaúcha. p. 224, "A crise atingia os pecuaristas, mas não todo o Estado, que possuía agora o recurso do arroz". Portanto, as áreas onde não predomina a criação de gado, como a região serrana, nâo encontravam problemas econômicos. Ver mapa da p. 09. Cel. Vazulmiro Dutra era um abastado fazendeiro da regiāo serrana de Palmeira, membro do PRR e comandante do $3^{\circ}$ Corpo Provisório. FELIX. Op. cit., p. 147-9. Ofício $n^{2} 24$, de 03.11.1924. Arquivo Vazulmiro Dutra. IHGRS. 
Um estudo sobre a participação dos Coronéis...

Tabela 1

Referente ao Gado Abatido pela $5^{g}$ Brigada Provisória do Centro, $1923^{26}$

\begin{tabular}{l|lr}
\hline UNIDADES & \multicolumn{2}{|c}{ QUANTIDADE DE ABATES } \\
\hline $1^{\circ}$ Corpo & Em 119 dias $-\quad 350$ reses \\
$2^{\circ}$ Corpo & Em 119 dias $-\quad 320$ reses \\
$3^{\circ}$ Corpo & Em 29 dias $-\quad 53$ reses \\
$4^{\circ}$ Corpo & Em 60 dias $-\quad 65$ reses \\
Contingente de Lavras & Em $\quad 77$ dias $-\quad 69$ reses \\
Contingentew de Rosário & Em $\quad 5$ dias $-\quad 5$ reses \\
$1^{\circ}$ Regimento de Cavalaria & Em 119 dias $-\quad 190$ reses \\
TOTAL & Em 119 dias -1.052 reses \\
\hline
\end{tabular}

Segundo o Cel Claudino, o mesmo relatório:

* (...) não há absoluta confiança nesses algarismos, por isso que, em grande parte baseiam-se em dados inseguros... porque as Unidades, acampadas longe uma das outras, à noite, às vezes com chuva, apressavam o mais possível a matança, não se podendo, nessas condições, verificar a quantidade exacta do gado abatido, muito menos a quem pertencia". ${ }^{27}$

Portanto, a tabela anterior não apresenta uma exatidão de números, conforme a confirmação do próprio comandante. Nestas condições, as aquisiçōes de gêneros alimentícios, principalmente o gado, efetuadas pelos Corpos nem sempre foram feitas de forma muito clara. E esta obscuridade por vezes poderia surtir benefícios.

26 Brigada Provisória do Centro. Indicaçōes dos lugares de estacionamento, de 18 de agosto a 20 de dezembro de 1923, com declaração do gado abatido. apresentada ao Comando Geral da Brigada pelo Cel. Claudino Nunes Pereira. Documentação nâo catalogada. MBM. Como pode-se observar nem todas as Unidades que formavam esta Brigada atuaram continuamente durante os 119 dias, entretanto, de uma forma geral tem-se a media de oito cabeças abatidas por dia.

$275^{\mathrm{a}}$ Brigada Provisória do Centro. Declaração do gado abatido, 18 de agosto à 20 de dezembro de 1923. MBM. Fl. 09. 
Segundo o Cel. Claudino, no mesmo relatório, o total de gado abatido com requisiçōes foi de 96 , e sem requisições, foram 956 cabeças. À primeira vista, a falta de requisição parece representar um empecilio para que o proprietário viesse a ser restituído; no entanto, esta situação acarretava alguma vantagem, se for considerado que, posteriormente, a restituição era efetuada após consulta ao comandante da Unidade citada pelo requerente, para a obtenção de um aval. Assim sendo, o pagamento era feito mediante a confirmação do comandante provisório.

É o que demonstra a carta enviada pelo Cel. Massot ao Cel. Juvêncio M. Lemos, solltando informações para efetuar um pagamento:

"Ao Sr. Coronel Graduado Juvêncio M. Lemos, Saudações.

Remeto-vos com esta, o requerimento em que Mário Borges de Leão, como procurador do Dr. Antônio Augusto de Assumpção, pede pagamento da quantia de 6:000 $\$ 000$ proveniente de 30 vacas fornecidas a $3^{\text {a }}$. Brigada Provisória do Sul, da qual fostes comandante, a fim de que se presteis as informações requisitadas pela Secretaria do Interior ...". ${ }^{28}$

Considerando-se que o abate de gado efetuado pelos CPs não era feito de uma forma organizada e precisa, pode-se entender que também não era possível confirmar com exatidão os quantitativos arrolados pelos requerentes. Neste caso as vantagens financeiras se referem à exatidão dos números e a possível ligação de "amizade" entre o solicitante e o informante, que seria o Comandante do CP.

Ainda pelo relatório do Cel. Claudino, se nota este aspecto, por exemplo, quando o mesmo se refere a algum proprietário conhecido, pois usa a palavra "coronel", o que indica haver uma ligação entre ambos.

Outubro, 07. Sesteada nas proximidades da "Cabanha Funda", onde são abatidas 04 rezes. Pouso na fazenda do coronel Secundino Barreto, no Seival. Foram abatidas 08 rezes não se dando requisiçāo." 29

Carta ñ 506, de 12.11.1924. Correspondência do Comando Geral. MBM.

$5^{g}$ Brigada Provisória do Centro. Declaração do gado abatido, de 18 de agosto à 20 de dezembro de 1923. MBM. Fl. 06. 
Quando era passada a requisição, as referências se davam de maneira mais distante, pois era usada a palavra "senhor" que indicava tratar se de pessoa pouco conhecida.

"Outubro, 29 (...) Pouso no Passo da "Conceição" $2^{\varrho}$ Districto de Rosário. Foram abatidas 08 rezes, pertencentes ao senhor Leonço Bragança, dando-se requisição". ${ }^{30}$

A ligação entre as partes justifica-se não só pelo exposto, mas também é possível determinar sua existência ao relacionar-se a quantidade de abates feitos sem requisições e a pessoa a quem pertencia o gado. Desta maneira, se pode constatar que aos "coronéis" não eram passadas requisiçōes; no entanto, a maior quantidade de gado abatido pertencia a estes proprietários.

Embora o Cel. Claudino explique que a matança era feita muitas vezes de forma fortuita, à noite, não sendo possível saber a quem pertencia o gado e, por este motivo, não eram passadas requisições, a análise quantitativa do relatório expedido ao Cel. Massot demonstra a seguinte situação:

"Agosto, 27. Sesteada e pouso próximo à fazenda "São Domingos". $1^{\circ}$ Districto de Lavras. Foram abatidas 10 rezes do coronel Hyppolito Souza, não se dando requisição.

- Agosto, 28. Sesteada e pouso próximo "Villa de Lavras". Foram abatidas 10 rezes do coronel Hyppolito Souza, não se dando requisição

- Setembro, 10. Sesteada e pouso na chácara de Joāo Cachapuz, $1^{\circ}$ Districto de Lavras. Foram abatidas 10 rezes, pertencentes ao coronel Hyppolito Souza, não se dando requisição.

- Setembro, 11. Parada no mesmo local. Foram abatidas 10 rezes, não se dando requisição.

- Setembro, 12. Pouso na fazenda "São Domingos", $1^{2}$ Districto de Lavras. Foram abatidas 10 rezes de propriedade do coronel Hyppolito Souza, não se dando requisição.

- Setembro, 13. Parada no mesmo local. Foram abatidas 10 rezes do coronel Hyppolito Souza, não se dando requisição.

- Setembro, 14. Pouso no passo de "São Domingos". $1^{\circ}$ Districto de Lavras. Foram abatidas 10 rezes do coronel Hyppolito Souza, não se dando requisição. (...)

Idem, fl. 08. 
- Outubro, 10 (...) foram abatidas 08 rezes pertencentes ao senhor coronel Hyppolito Souza, não se dando requisição.

- Outubro, 11. Foram abatidas 06 rezes pertencentes ao coronel Hyppolito Souza, não se dando requisição" ${ }^{31}$

Pelo exposto nesta situação, não haveria motivo para que não fossem requisitadas as 84 cabeças de gado do coronel Hyppolito pois era sabido o nome do proprietário e, possivelmente, repetidas vezes o mesmo deve ter tido contato com as forças do Cel. Claudino. Inclusive é possível notar que havia um relacionamento mais estreito entre ambos, na medida em que um contingente da mesma localidade, Lavras, fazia parte da Brigada do Centro (ver Tabela 1).

Uma explicação plausível para este caso seria a de que o referido coronel Hyppolito tenha "doado" os animais a $5^{2}$ Brigada do Centro. No entanto, para um número tão elevado, considerando-se a época de crise econômica, esta hipótese não parece consistente.

Devido a inexatidão dos números, às incertezas e à falta de informações sobre os abates, as restituiçōes posteriores dependeriam da confirmação do Cel. Claudino. Este, por sua vez, não teria condições de negar possíveis alterações nos números apresentados.

A questão das requisições, suas obscuridades e as incertezas que as emaranhavam, traziam benefícios até mesmo ao Cel. Massot reconhecido apreciador de cavalos. Em algumas oportunidades, quando as forças provisórias "conseguiam" cavalos de raça, tomados dos "inimigos'; o referido coronel determinava que o animal fosse transportado para a capital, e posteriormente iria averiguar a quem pertencia.

Em carta de 05.05.1925, o Cel. Massot versa sobre um cavalo purosangue, enviado à capital pelas forças provisórias, pois teria sido tomado dos "rebeldes". Como haviam indicações do possível dono, a atitude do comandante geral da BM, foi a de mandar algumas fotos do cavalo ao Intendente de Ijuí, para que este verificasse "se o dono reconhece as fotos que enviou, se não, o cavalo ficará na Brigada". ${ }^{32}$ Isto, tendo explicado anteriormente que o referido animal chegou a Brigada em estado precário, magro. Estando agora em ótimo estado, devido aos bons cuidados.

A questão das requisições, aqui apresentada, de maneira apenas exemplar, indica a existência de interesses individuais que eram viabilizados

$315^{g}$ Brigada Provisória do Centro. Declaração do gado abatido, de 18 de agosto à 20 de dezembro de 1923. MBM. Fl. 1-8.

Carta n 111, de 05.05.1925. Correspondência do Comando Geral. MBM. 
através dos CPs. Neste sentido, o que se tentou demonstrar, para o contexto abordado, é que os coronéis borgistas obtiveram em seu proveito um efeito maior de poder. Isto deu-se porque os mesmos tinham uma maior proximidade com as lideranças do aparelho do Estado e utilizavam os mecanismos (CPs), para a consecução de seus objetivos pessoais e imediatos.

\section{REFERÊNCIAS BIBLIOGRÁFICAS}

ANTONACCI, Maria A. RS as Oposições \& a Revolução de 1923. Porto Alegre: Mercado Aberto, 1981.

BOEIRA, nelson. RS Cultura e Ideologia. Porto Alegre: Mercado Aberto, 1980.

FELIX, Loiva O. Coronelismo-Borgismo e Cooptação Política. Porto Alegre: Mercado Aberto, 1987.

FERREIRA, Filho, Arthur. Revolução de 1923. Porto Alegre: Imprensa Oficial, 1973. FOUCAULT, Michel. Microfísica do Poder. 9. E. Rio de Janeiro: Graal, 1990.

LACQUES, Alfredo. Os Provisórios. Porto Alegre: Globo, 1938.

MARIANTE, Hélio Moro. Crônica da Brigada Militar Gaúcha. Porto Alegre: Imprensa Oficial, 1972.

PESAVENTO, Sandra. República Velha Gaúcha. Charquadas - Frigoríficos-Criadores. Porto Alegre: Movimento, 1980, p. 178.

RIBEIRO, Aldo Ladeira. Esboço Histórico da Brigada Militar. Porto Alegre: Oficinas Gráficas da Brigada Militar, 1953, v. 2, p. 56.

SANTOS, Mariza Elaine S. Dissertação de Mestrado. História do Brasil, 1988.

VIZENTINI, Paulo F. A Crise dos Anos 20. Porto Alegre: Editora da Universidade Federal do RS., 1992. 